\title{
Comparison between laparoscopy and laparotomy in the management of ectopic pregnancy: a retrospective study
}

\author{
Suneeta Singh ${ }^{1}$, Namrita Sandhu ${ }^{1 *}$, Sanjay Singh ${ }^{1}$, Praveen Kumar ${ }^{2}$, Atiya Aziz
}

\begin{abstract}
${ }^{1}$ Department of Obstetrics and Gynecology, Army College of Medical Sciences, Delhi Cantt, Delhi, India
${ }^{2}$ Department of Obstetrics and Gynecology, Command Hospital, Pune, Maharashtra, India
\end{abstract}

Received: 29 November 2019

Accepted: 31 December 2019

*Correspondence:

Dr. Namrita Sandhu,

E-mail: sandhu.namrita@gmail.com

Copyright: (C) the author(s), publisher and licensee Medip Academy. This is an open-access article distributed under the terms of the Creative Commons Attribution Non-Commercial License, which permits unrestricted non-commercial use, distribution, and reproduction in any medium, provided the original work is properly cited.

\begin{abstract}
Background: Ectopic pregnancy is one of the most important causes of maternal mortality and morbidity in the first trimester of pregnancy. Objective of this study was to compare the safety, feasibility and advantage of laparoscopic approach with that of laparotomy in management of ectopic pregnancy.

Methods: A retrospective study was conducted at two tertiary hospitals over a period of two years i.e.; from Aug 2015 to July 2017. Seventy-five patients who had histopathology confirmed tubal ectopic pregnancy were divided into two groups; laparoscopy (Group I, no-39) and laparotomy (Group II no-36). The main outcome measures were operative time, blood loss, and requirement of blood transfusion, requirement of analgesia and duration of hospital stay.

Results: Seventy-five patients of ectopic pregnancy who were managed surgically were studied. There were 39 cases in laparoscopy group and 36 cases in laparotomy group. The incidence of ectopic pregnancy was $1.56 \%$ (out of all deliveries over 2 years). Ampullary region was the commonest site of ectopic pregnancy (74.6\%). No difference was found in the two groups regarding age, site of tubal pregnancy, pre op $\mathrm{Hb}$ status and haemoperitoneum. Mean operating time was significantly shorter in the laparoscopy group 39 min (range 30 - 52 min) versus 50 min (range 40 $60 \mathrm{~min}$ ) in the laparotomy group. There was no difference between the groups regarding the treatment with blood products and perioperative complications. Hospital stay was significantly longer in the laparotomy group (3.5 days) as compared to 2 days in laparoscopy group. The duration of post op analgesia requirement was also longer in laparotomy group (4 days) as compared to 2 days in laparoscopy group.

Conclusions: Laparoscopic management of ectopic pregnancy is a safe, effective and beneficial option in the hands of an experienced laparoscopic surgeon even in cases of massive haemoperitoneum. It definitely offers the advantage of shorter duration of surgery, faster post op recovery, shorter duration of hospital stays and lesser requirement of post op analgesia.
\end{abstract}

Keywords: Ampula, Ectopic pregnancy, Haemoperitoneum, Laproscopy, Laparotomy

\section{INTRODUCTION}

Ectopic pregnancy is one of the most important causes of maternal mortality and morbidity in the first trimester of pregnancy. The incidence of ectopic pregnancy is 1.3 to $2 \%$ of the reported pregnancies in US. ${ }^{1}$ It accounts for $6 \%$ of all pregnancy related deaths., ${ }^{2,3}$ With the advent of sensitive and specific radio immunoassay (RIA) for $\beta h C G$ and easy availability of transvaginal sonography most of the cases of ectopic pregnancies are diagnosed early, leading to better maternal survival rates and improved reproductive capacity. But still in developing 
countries, there is a delay in the diagnosis with a lot of ectopic pregnancies being diagnosed after rupture.

Ectopic pregnancy is a clinical condition which can be managed by many ways i.e.; expectantly, medically and surgically depending on the patient's presentation, haemodynamic status, $\beta$ hCG value, ultrasound report and the expertise of the surgeon. But till date surgery remains the mainstay of treatment. ${ }^{4}$ Laparoscopy is the preferred surgical treatment for ectopic pregnancy unless a woman is haemodynamically unstable. ${ }^{5}$ The route of surgery would depend upon the availability of resources, skill of the surgeon and definitely the haemodynamic status of the patient. Improved anaesthesia and cardiovascular monitoring, together with advanced laparoscopic surgical skills and experience, justifies operative laparoscopy for surgical treatment of ectopic pregnancy even in women with significant haemoperitoneum. ${ }^{6-9}$

A dramatic shift towards laparoscopic management is evident over the last one and half decade as it offers advantage over open approach in terms of shorter operative time, less blood loss, less analgesia requirement and shorter hospital stay. ${ }^{10-12}$ It is also associated with significantly lower cost. ${ }^{13}$ The present study studied the efficacy and advantage of laparoscopic approach over laparotomy in the management of ectopic pregnancy.

\section{METHODS}

A retrospective observational study was conducted at two zonal hospitals of Indian Army over two years from August 2015 to July 2017. Medical records of all the patients who underwent surgery for ectopic pregnancy at the study centre from 01 August 2015 to 31 July 2017 were reviewed. During this period 75 cases of histopathology confirmed ectopic pregnancy were surgically managed. Patients age, parity, pre-op haemoglobin levels were recorded. Thirty-nine patients were managed by laparoscopic approach and thirty-six patients were managed by laparotomy. The decision regarding the route of surgery was taken by the attending surgeon based on the vitals of the patient, haemoglobin levels and their surgical expertise in laparoscopic surgery. The laparoscopic surgery was performed under general anaesthesia. While majority (no. 29) of the cases in the Laparotomy group were given spinal anaesthesia, seven cases had to be given general anaesthesia. In both groups all the patients underwent salpingectomy.

\section{Inclusion criteria}

- $\quad$ Age 18-45 years old

- Confirmed ectopic pregnancy on ultrasound

- Giving consent and having signed the consent form for this study

- Patients with confirmed histopathology report.

\section{Exclusion criteria}

- $\quad$ Patients with failed medical management

- With co-morbidities, e.g. hypertension, heart disease, peptic ulcer etc.

- Heterotopic pregnancy.

\section{Statistical analysis}

The statistical calculations were performed with SPSS software. A 2-tailed $\mathrm{p}<0.05$ was defined as statistically significant.

\section{RESULTS}

It was observed that the demographic variables (mean age group) were well matched in both the groups. The most common age group of presentation in our study was 1825 years. Very few patients were in the age group $>31$ years. Age differences in the two groups were not significant (Table 1).

Table 1: Age wise distribution in the two groups.

\begin{tabular}{|lllll|}
\hline Age (years) & Group I laparoscopy & Percentage & Group II laparotomy & Percentage \\
\hline $18-25$ & 26 & 34.6 & 22 & 29.3 \\
\hline $26-30$ & 08 & 10.6 & 09 & 12 \\
\hline$>31$ & 05 & 6.6 & 05 & 16.6 \\
\hline Total & $\mathbf{3 9}$ & $\mathbf{5 2}$ & $\mathbf{3 6}$ & $\mathbf{4 8}$ \\
\hline
\end{tabular}

Table 2: Frequency of site of tubal ectopic pregnancy.

\begin{tabular}{|lllll|}
\hline Site of ectopic & Group I laparoscopy & Percentage & Group II laparotomy & Percentage \\
\hline Ampullary & 32 & 42.6 & 24 & 32 \\
\hline Isthmic & 07 & 9.33 & 11 & 14.6 \\
\hline Cornual & Nil & Nil & 01 & 1.3 \\
\hline Total & $\mathbf{3 9}$ & $\mathbf{5 2}$ & $\mathbf{3 6}$ & $\mathbf{4 8}$ \\
\hline
\end{tabular}


In our study we found that, ampulla was the most common site of ectopic pregnancy in both the groups with isthmic part of the tube being the second most common site (Table 2).
The pre-operative $\mathrm{Hb}$ was comparable in both the groups (Table 3) with the majority of patients having moderate anemia between $7 \mathrm{gm} \%$ to $8.9 \mathrm{gm} \%$. Less than $10 \%$ of the patients in both the groups were severely anaemic at the time of surgery.

Table 3: Pre-operative $\mathrm{Hb}$ wise distribution in the two groups.

\begin{tabular}{|lllll|}
\hline Hb $($ gm \%) & Group I laparoscopy & Percentage & Group II laparotomy & Percentage \\
\hline $9-11$ & 11 & 14.66 & 11 & 14.66 \\
\hline $7-8.9$ & 21 & 21 & 18 & 24 \\
\hline$<7$ & 07 & 9.3 & 07 & 9.3 \\
\hline Total & $\mathbf{3 9}$ & $\mathbf{5 2}$ & $\mathbf{3 6}$ & $\mathbf{4 8}$ \\
\hline
\end{tabular}

Table 4: Haemoperitoneum status.

\begin{tabular}{|lllll|}
\hline Volume $(\mathbf{m l})$ & Group I laparoscopy & Percentage & Group II laparotomy & Percentage \\
\hline $100-500$ & 11 & 14.66 & 09 & 12 \\
\hline $500-1000$ & 22 & 29.33 & 18 & 24 \\
\hline $1000-1500$ & 06 & 8 & 09 & 12 \\
\hline Total & $\mathbf{3 9}$ & $\mathbf{5 2}$ & $\mathbf{3 6}$ & $\mathbf{4 8}$ \\
\hline
\end{tabular}

Table 5: Outcome measures (perioperative complications).

\begin{tabular}{|lllll|}
\hline Groups & $\begin{array}{l}\text { Mean duration } \\
\text { of surgery }\end{array}$ & $\begin{array}{l}\text { Mean hospital } \\
\text { stay }\end{array}$ & $\begin{array}{l}\text { Post op analgesia } \\
\text { reqt }\end{array}$ & $\begin{array}{l}\text { Blood transfusion } \\
\text { 2 X PRBC }\end{array}$ \\
\hline I (laparoscopy) & $39 \min (30-52)$ & 02 days & 02 days & $16(42 \%)$ \\
\hline II (laparotomy) & $45 \min (40-60)$ & 3.5 days & 04 days & $14(45 \%)$ \\
\hline
\end{tabular}

There wasn't much difference in the clinical presentation of the patients in the two groups. In both the groups, almost all the patients presented with a certain degree of hemoperitoneum. About 6 patients in the laparoscopic group and 9 in the laparotomy group had massive hemoperitoneum (Table 4).

We found that the mean duration of surgery was much shorter (39 $\mathrm{min}$ ) in the laparoscopy group where as it was about 45 minutes in the laparotomy group. The hospital stay was about 2 days for patients who underwent laparoscopy as compared to 4 days in the laparotomy group. This shorter duration of hospital stay and convalescence, offered a great advantage to the patients in the laparoscopic group in terms of economic benefits and a faster recovery.

Further, laparoscopy patients required post op analgesia for a much shorter duration compared to the laparotomy group (2 days versus 4 days). 16 patients in the laparoscopy group required blood transfusion as compared to about 14 in the laparotomy group (Table 5).

Over all we were successful in tackling all cases of ruptured ectopic pregnancy, even the ones that presented with massive hemoperitoneum, laparoscopically. However, laparoscopic approach was attempted in only 39 cases as it was subject to the availability of a trained laparoscopic surgeon and laparoscopic instruments which could be a challenge in peripheral hospitals, where lap set or expertise is not available.

\section{DISCUSSION}

Ectopic pregnancy is a common gynaecological emergency which if diagnosed early and managed timely can decrease maternal mortality and morbidity significantly. The incidence of ectopic pregnancy has increased from $0.5 \% 30$ years ago to a current incidence of $1.3 \%$ to $2 \% .^{1}$ The first open salpingectomy was done by Tait RL et al in Scotland and till date most of the gynaecologists are well versed with the laparotomy approach of managing ectopic pregnancy.

It was almost after one century in 1973 that Shapiro and Adler described laparoscopic management of ectopic pregnancy. ${ }^{14}$ Since then the technical advancement in the field of minimal access surgery has greatly enhanced the possibility of both diagnosing and treating ectopic pregnancy effectively. As it offers advantage over laparotomy, now it has become the standard of care in the management of ectopic pregnancy..$^{12,13,15-17}$ Not only is salpingectomy considered a treatment option, but surgical interventions like salpingostomy and salpingotomy which offer the advantage of preservation of the fallopian tube are gaining popularity as treatment options, especially in 
nulliparous women. However, the laparoscopic approach for most cases of ectopic pregnancy and salpingectomy is preferred over salpingostomy if the contralateral tube is healthy. ${ }^{18}$

Laparoscopy is now the preferred management method in most cases of ruptured ectopic. However, in women who are hemodynamically unstable, the role of laparoscopy remains controversial. But with increasing expertise in laparoscopic surgery, even in the presence of a large hemoperitoneum, operative laparoscopy is still achievable. ${ }^{8,9,19}$ In our study six cases of ruptured ectopic with massive haemoperitoneum were managed laparoscopically without any surgical complication.

In our study the mean duration of surgery was shorter in the laparoscopy group $39 \mathrm{~min}$ (range 30-52 min] versus $50 \mathrm{~min}$ (range 40-60 $\mathrm{min}$ ) in the laparotomy group as seen in few other studies too. ${ }^{8,12}$ In the study by Jahan $S$ et al, the duration of operation in the laparoscopy group was $53.2 \pm 16.8$ minutes and $84.5 \pm 30.3$ minutes in the laparotomy group. In another study by Cohen et al, median operating time was significantly shorter in the laparoscopy group [50 minutes (range, 43-63 minutes) versus 60 minutes (range, 60-72 minutes) $\mathrm{p}=0.01]$. Thus, we can safely conclude that laparoscopic surgery does offer the advantage of shorter operating time.

There was no difference between the groups regarding the treatment with blood products and perioperative complications. In our study, the hospital stay was significantly longer in the laparotomy group (3.5 days) as compared to 2 days in laparoscopy group which corroborates with other studies. ${ }^{10,15,20}$ The study done by Jahan et al, suggests that the duration of hospitalization was significantly shorter in the laparoscopy group $1.12 \pm 0.5$ days compared to $5.25 \pm 0.1$ days in the laparotomy group $(\mathrm{p}<0.0001)$.

The duration of post op analgesia requirement was also longer in laparotomy group (4 days) as compared to 2 days in laparoscopy group which has been reflected in other studies too. ${ }^{10,15,20}$ In the study conducted by Jahan et al, in the laparoscopy group $57(72.4 \%)$ patients did not need analgesia after surgery compared with laparotomy group where all the patients needed analgesia. In the present study we have shown that ruptured ectopic with massive haemoperitoneum (1000-1500 ml) can be managed successfully by laparoscopy too as was seen in the study by Cohen et al and Sagiv R and Takeda. . $^{8,9,21}$

Thus, with adequate experience in laparoscopy, i.e., with an experienced laparoscopic surgeon and with proper instruments, most if not all of the patients with ectopic pregnancy can be treated successfully, whatever the gestation size or location, the number of gestations, or the presence of tubal rupture as seen in study by Chaudhury $\mathrm{P}$ and Ding DC. ${ }^{15,16}$

\section{CONCLUSION}

A higher percentage of ectopic pregnancies can be managed laparoscopically if minimal access surgery experience is introduced in all the surgical units. Although this study is limited by its retrospective nature, it supports the idea that laparoscopic management of ectopic pregnancy might be the most beneficial procedure with maximal safety and efficacy. Laparoscopic management of ectopic pregnancy is a safe, effective and beneficial option in the hands of an experienced laparoscopic surgeon even in cases of massive haemoperitoneum. It definitely offers the advantage of shorter duration of surgery, faster post op recovery, shorter duration of hospital stay and lesser requirement of post op analgesia.

\section{Funding: No funding sources}

Conflict of interest: None declared

Ethical approval: The study was approved by the Institutional Ethics Committee

\section{REFERENCES}

1. Zane SB, Kieke BA, Kendrick JS, Bruce C. Surveillance in a time of changing health care practices: estimating ectopic pregnancy incidence in the United States. Maternal Child Health J. 2002;6:227.

2. Berg CJ, Callaghan WM, Syverson C, Callaghan WM, Syverson C, Henderson Z. Pregnancy-related mortality in the United States, 1998-2005. Obstet Gynecol. 2010;116:1302.

3. Stulberg DB, Cain LR, Dahlquist I, Lauderdale DS. Ectopic pregnancy rates in the Medicaid population. Am J Obstet Gynecol. 2013;208(4):274.e1.

4. Hajenius PJ, Mol BW, Bossuyt PM, Ankum WM, Van Der Veen F. Interventions for tubal ectopic pregnancy. Cochrane Database Syst Rev. 2000:CD000324.

5. Ectopic Pregnancy. In:Williams Obstetrics: Cunningham, Leveno eds. $24^{\text {th }}$ ed. New York, NY: McGraw-Hill; 2014:385.

6. Rizzuto MI, Oliver R, Odejinmi F. Laparoscopic management of ectopic pregnancy in the presence of a significant haemoperitoneum. Arch Gynecol Obstet. 2008;277(5):433-6.

7. Beuran M, Negoi I, Hostiuc S, Catena F, Sartelli M, Negoi RI, et al. Laparoscopic approach has benefits in gynecological emergencies - even for massive hemoperitoneum. Chirurgia. 2016;111:48-53.

8. Cohen A, Almog B, Satel A, Lessing JB, Tsafrir Z, Levin I. Laparoscopy versus laparotomy in the management of ectopic pregnancy with massive hemoperitoneum. Int J Gynaecol Obstet. 2013;123(2):139-41.

9. Takeda A, Manabe S, Mitsui T, Nakamura $H$. Management of patients with ectopic pregnancy with massive hemoperitoneum by laparoscopic surgery 
with intraoperative autologous blood transfusion. J Minim Invasive Gynecol. 2006;13:43-8.

10. Jahan S, Das TR. A comparative study between laparoscopic management of ectopic pregnancy and laparotomy: experience in tertiary care hospital in bangladesh: a prospective trial. Bangladesh J Endosurg. 2014;2(1).

11. Saleh AM, Mahjoub MM, El-Kurdy AM. Laparoscopy versus laparotomy management of tubal pregnancy. Saudi Med J. 2001;22(9):771-5.

12. Lundorff $\mathrm{P}$, Thorburn J, Hahlin M, Kallfelt B, Lindblom B. Laparoscopic surgery in ectopic pregnancy. A randomized trial versus laparotomy. Acta Obstet Gynecol Scand. 1991;70:343-8.

13. Hajenius PJ, Mol BW, Bossuyt PM, Ankum WM, Van Der Veen F. Interventions for tubal ectopic pregnancy. Cochrane Database Syst Rev. 2000;(2):CD000324.

14. Shapiro HL, Adler DH. Excision of an ectopic pregnancy through the laparoscope. Am J Obstet Gynaecol. 1973;117:290.

15. Ding DC, Chu TY. Laparoscopic management of tubal ectopic pregnancy. J Societ Laparoendosco Surg. 2008;12(3):273-6.

16. Chaudhary P, Manchanda R, Patil VN. Retrospective study on laparoscopic management of ectopic pregnancy. J Obstet Gynaecol India. 2013;63(3):1736.
17. Shrestha J, Saha R. Comparison of laparoscopy and laparotomy in the surgical management of ectopic pregnancy. J Coll Physicians Surg Pak. 2012;22(12):760-4.

18. Mohamed H, Maiti S, Phillips G. Laparoscopic management of ectopic pregnancy: a 5-year experience. J Obstet Gynaecol. 2002;22:411-4.

19. Rizzuto MI, Oliver R, Odejinmi F. Laparoscopic management of ectopic pregnancy in the presence of a significant haemoperitoneum. Arch Gynecol Obstet. 2008;277(5):433-6.

20. Duggal BS. Laparoscopic management of ectopic pregnancies. MJAFI. 2004;60:220-3.

21. Sagiv R, Debby A, Sadan O, Malinger G, Glezerman M, Golan A. Laparoscopic surgery for extrauterine pregnancy in hemodynamically unstable patients. J Am Assoc Gynecol Laparosc. 2001;8(4):529-32.

Cite this article as: Singh S, Sandhu N, Singh S, Kumar P, Aziz A. Comparison between laparoscopy and laparotomy in the management of ectopic pregnancy: a retrospective study. Int J Reprod Contracept Obstet Gynecol 2020;9:705-9. 